DOI: https://doi.org/10.24867/13FA04Milic

\title{
PROJEKTOVANJE ENTERIJERA KAFETERIJE U SKLADU SA AFINITETIMA KORISNIKA
}

\section{COFFEE SHOP INTERIOR DESIGN IN ACCORDANCE WITH USER AFFINITIES}

\author{
Dragana Milić, Fakultet tehničkih nauka, Novi Sad
}

\section{Oblast - ARHITEKTURA I URBANIZAM}

Kratak sadržaj - Kako bi se uspešno dizajnirao prostor trećeg mesta, odnosno mesta okupljanja, trebalo bi razumeti socijalne $i$ fizičke karakteristike mesta koji poboljšavaju iskustvo korisnika, što predstavlja i sam cilj ovog istraživanja. Boljim razumevanjem tih karakteristika koje doprinose pozitivnom doživljaju mesta, mogu se stvoriti prostori koji promovišu udobnost, osećaj pripadnosti i povezanost između ljudi i samih prostora. Pored predstavljanja "Okvira pozitivnog dizajna", istraživačkog rada P. Desmet i A. Pohlmeyer, istražiće se fizičke $i$ društvene karakteristike koje utiču na to da se ljudi okupljaju $i$ razvijaju povezanost sa prostorom (trećeg mesta).

Ključne reči: kafeterija, enterijer, dizajn za zadovoljstvo, okvir pozitivnog dizajna

\begin{abstract}
In order to successfully design a third place space, ie a gathering place, one should understand the social and physical characteristics of the place that improve the user experience, which is the purpose of this research. By better understanding these characteristics that contribute to a positive experience of the place, spaces can be created that promote comfort, a sense of belonging and connection between people and the spaces themselves. In addition to the presentation of the "Positive Design Framework", research work by $P$. Desmet and A. Pohlmeyer, the physical and social characteristics that influence people to come together and develop a connection with space (third place) will be explored.
\end{abstract}

Keywords: coffee shop, interior design, design for pleasure, positive design framework

\section{UVOD}

Ovaj rad će se posebno usredsrediti na potencijal za dizajniranje unutrašnjih prostora, $u$ ovom slučaju kafeterije, koja podržavaju ugodna i sadržajna iskustva i na taj način doprinose dobrobiti ljudi, odnosno svrha ove studije jeste istraživanje fizičkih i društvenih kvaliteta koja su podsticala ljude da se okupljaju, zadržavaju i razvijaju povezanost sa tim mestima.

U prvom delu rada biće predstavljena studija koja je istraživala karakteristike koje podstiču na okupljanje i

\section{NAPOMENA:}

Ovaj rad proistekao je iz master rada čiji mentor je bio dr Marko Todorov, vanr.prof. stvaraju osećaj povezanosti sa odabranim prostorom kafeterijom. Obuhvatala je istraživačke tehnike vizuelne dokumentacije, posmatranje i mapiranje ponašanja, kao i anketu. Ključni rezultati $u$ vezi sa fizičkim karakteristikama pokazuju prvih pet faktora koji se uzimaju u obzir pri dizajniranju, i tu spadaju: čistoća, udoban mobilijar, dostupnost prirodnog svetla, aroma / mirisi i vizuelno privlačan nameštaj. Utvrđene su socijalne karakteristike korisnika, i predstavljeno je na koji način dizajn prostora može da utiče na čoveka.

U drugom delu rada biće predstavljena nova tema istraživanja $\mathrm{u}$ polju nauka o dizajnu - subjektivno blagostanje (SVB), kako bi se dizajn samih prostora razvijao u nastojanju da povećava dobrobit korisnika, kao i tema ,treća mesta“, odnosno važnost neformalnih javnih okupljališta.

Prikazivanje ovih aspekata (okvir pozitivnog dizajna, fizičke karakteristike kafeterije i socijalne karakteristike korisnika) predstavaljaju pomoćni alat pri dizajniranju kafeterije prema potrebama korisnika.

\section{METODE ISTRAŽIVANJA}

\subsection{Studije slučaja}

Za studije slučaja izabrana su tri prostora kafeterije, dok je za njihovu analizu pored vizuelne dokumentacije i sesije posmatranja, korišćena anketa kao metoda istraživanja.

Ova dokumentacija se sastoji od prikupljenih informacija o fizičkim karakteristikama kafeterije, uključujući lokaciju kafeterije i arhitektonske i dizajnerske atribute svake kafeterije. Uzeće se u obzir aspekti kao što su pristup prirodnom osvetljenju, vrsta veštačkog osvetljenja, materijali, vrsta nameštaja, lokacija električnih utičnica, pogledi ka spolja, pogledi na prostore iznutra, funkcionisanje u prostoru i podela prostora na zone, i kako zapravo celokupni ambijent utiče na posetioca lokala.

\subsection{Sesije posmatranja}

Sesije posmatranja pomogle su u razumevanju kako su kafeterije korišćene i kako je dizajn prostora povezan sa aktivnostima koje su se odvijale u prostoru. $\mathrm{Na}$ osnovu posmatranja cilj je bio otkriti osnovnu nameru boravka posetioca u prostoru, odnosno otkriti značenje prostora za samog korisnika. 
Mesta u blizini prozora, ili mesta za sedenje sa pogledom na veći deo unutrašnjosti su takođe bila veoma poželjna, gde su se posmatrali prolaznici, kao i dolazak i odlazak drugih korisnika.

Postojao je i odabir sedišta iz praktičnih razloga. Sedišta su birana u zavisnosti od zadataka koje su trebali da obave, bilo to $\mathrm{u}$ blizini utičnica, ili mesta sa odgovarajućim osvetljenjem. Dok je za grupu ljudi na izbor sedišta uticala mogućnost mobilnosti nameštaja i veličina stola.

U slučaju Kafeterije 1 i 2 stolovi i mesta za sedenje su postavljeni prilično blizu jedni drugima, kako bi se maksimalno iskoristio raspoloživi prostor.

Blisko postavljene stolove su korisnici birali u slučaju kad je to bilo jedino slobodno mesto, i rezultiralo je znatno kraćim zadržavanjem u kafeteriji. Gledajući sa psihološkog aspekta, zadovoljstvo korisnika je takođe smanjeno, uzrokovano nedostatkom ličnog prostora.

Mesta za sedenje koja su pozicionirana u centralnom delu prostora, bez naročite fizičke barijere, korisnici su neretko birali, a pretežno su to bili korisnici koji su došli sami.

Pored toga što je ovakav vid mesta za sedenje bio nepogodan za korisnike koji su u kafeteriju došli sa svrhom da obave neku vrstu posla, zbog nedostatka utičnica, stvarao je i osećaj nelagodnosti, jer nisu postojale fizičke strukture koje su stvarale osećaj sigurnosti kod čoveka.

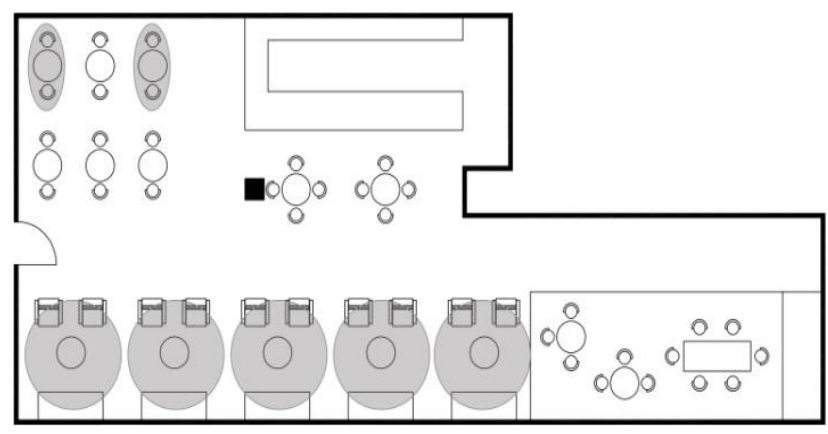

Slika 1. Osnova Kafeterije 1 - najpoželjnija mesta za sedenje [1]

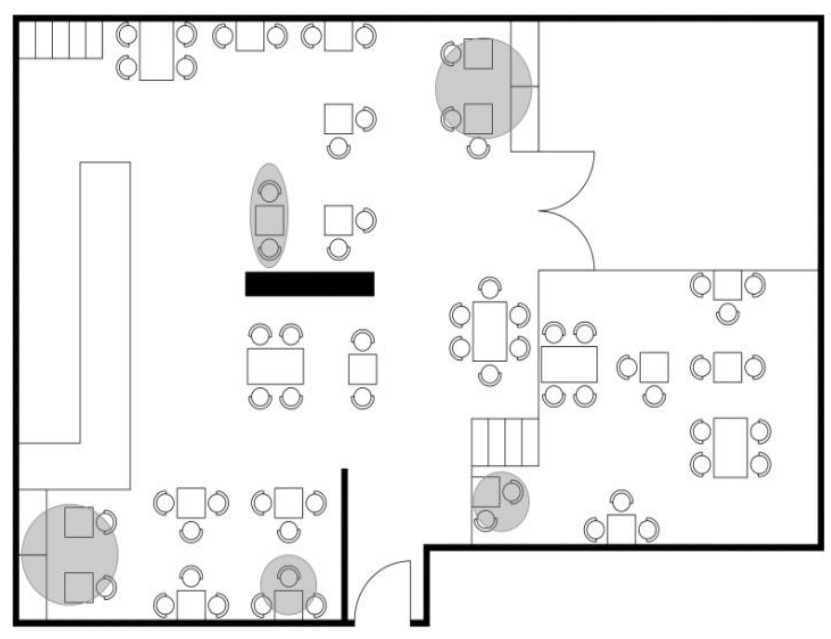

Slika 2. Osnova Kafeterije 2 - najpoželjnija mesta za sedenje [2]

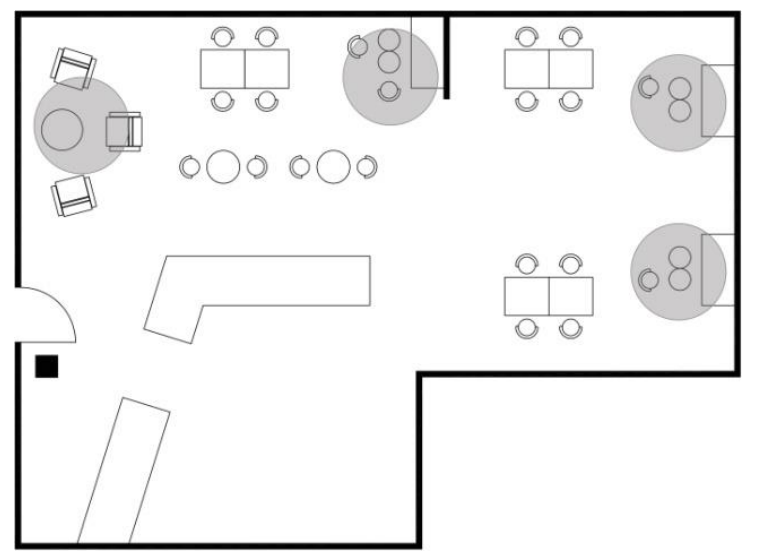

Slika 3. Osnova Kafeterije 3 - najpoželjnija mesta za sedenje [3]

\subsection{Anketa}

Anketa je obuhvatala pitanja kao što su socijalizacijske namere korisnika, dok je drugi deo ankete tražio od posetioca da zaokruži koje fizičke karakteristike bi želeli da vide u svom idealnom prostoru kafeterije. Postavljana su pitanja o karakteristikama njihovog idealnog prostora kafeterije, tako da bi istraživač mogao da identifikuje one atribute koji su bili visoko cenjeni i koji su možda čak nedostajali u kafeteriji koji posećuju.

Fizičke karakteristike - pet najvažnijih faktora koje su ljudi ocenili kao bitne za idealan enterijer kafeterije: čistoća $(96,7 \%)$, udoban mobilijar $(76,7 \%)$, dostupnost prirodnog svetla $(61,7 \%)$, aroma / mirisi $(51,7 \%)$ i vizuelno privlačan nameštaj $(48,3 \%)$.

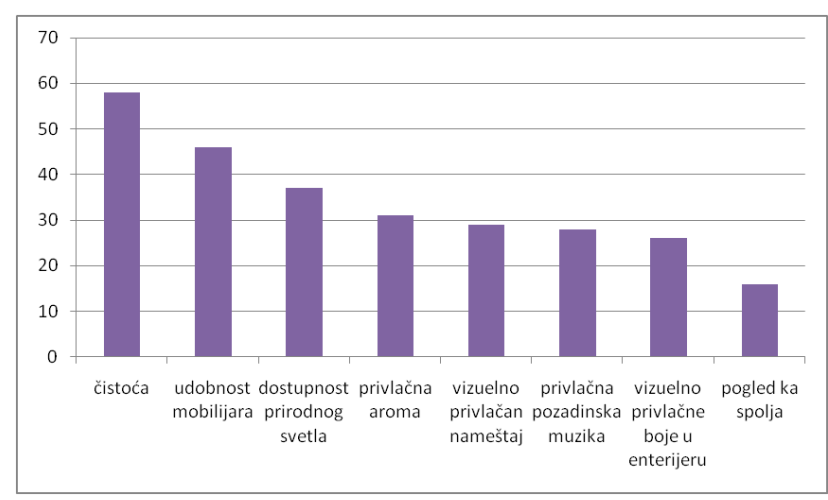

Slika 4. Rezultati ankete - fizičke karakteristike idealnog enterijera kafeterije [4]

Socijalne karakteristike - da bismo adekvatno oblikovali prostor, potrebno je da razumemo socijalnu kulturu korisnika, i njihove socijalne namere.

$\mathrm{Na}$ osnovu izvršenih anketa utvrđeno je da korisnici u najvećem procentu retko komuniciraju sa drugim posetiocima/korisnicima $(63,3 \%)$, kao i sa zaposlenim licima $(51,7 \%)$. Ove socijalne karakteristike nam govore da se radi o većem procentu introvertnih tipova ličnosti, koje se radije odlučuju za društvo poznatih korisnika, uživanje u atmosferi samo posmatrajući druge korisnike bez interakcije, ili se odlučuju za boravak u prostoru radi obavljanja ličnih zadataka/obaveza. 


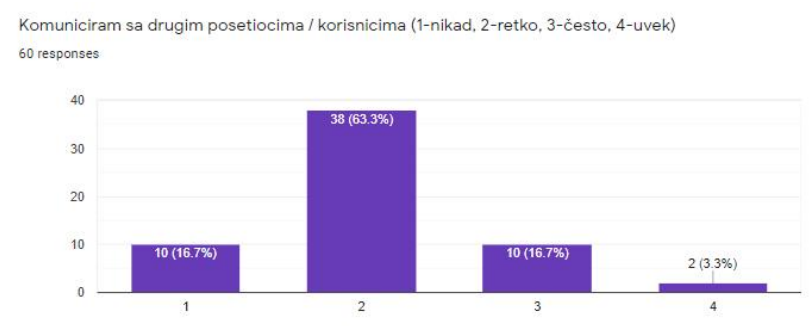

Slika 5. Rezultati ankete - komunikacija sa drugim posetiocima [5]

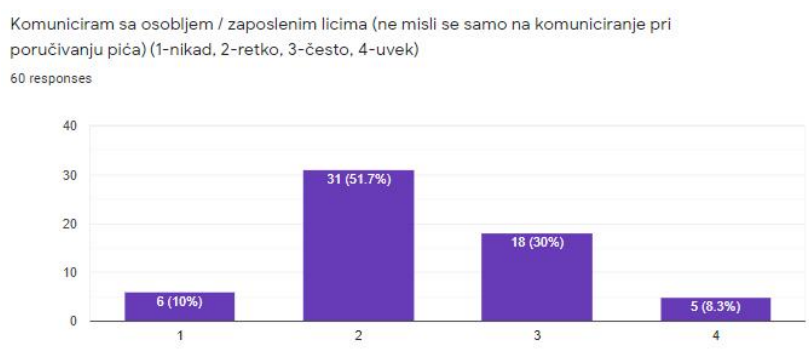

Slika 6. Rezultati ankete - komunikacija sa zaposlenim licima [6]

Anketa takođe pokazuje da se mogućnost organizovanja grupnih sastanaka kod skoro polovine ispitanika pokazala kao veoma važan faktor $(48,3 \%)$ kod projektovanja prostora kafeterije.

Pogled ka drugim posetiocima je ocenjen približno isto, sa odgovorom delimično važno $(40 \%)$ i veoma važno (35\%). Iako su rezultati pokazali da u najvećem procentu korisnici retko komuniciraju sa drugim nepoznatim korisnicima, pogled ka istima je delimično, a kod nekih veoma važan, što pokazuje da je samo prisutvo u prostoru sa drugim ljudima dovoljno da bi se korisnik osećao na neki način socijalizovano, i da ga samo njegovo egzistiranje u prostoru potvrđuje kao člana zajednice.

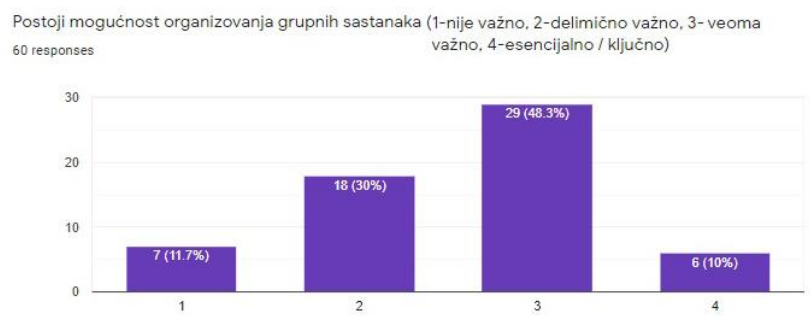

Slika 7. Rezultati ankete - mogućnost organizovanja grupnih sastanaka [7]

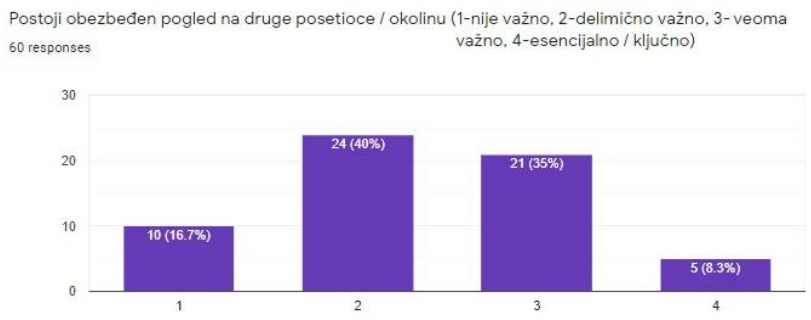

Slika 8. Rezultati ankete - pogled ka drugim posetiocima [8]

\section{PRETHODNA ISTRAŽIVANJA}

U istraživačkom radu se spominje urbani sociolog Rai Oldenburg, koji piše o važnosti neformalnih javnih okupljališta, koja naziva „treća mesta“, koja su kao socijalna sredina odvojena od uobičajena dva mesta doma ("prvo mesto") i radnog mesta ("drugo mesto"). Pokazuje kako su i zašto ta mesta od suštinskog značaja za zajednicu i javni život, tvrdeći da su barovi, kafići, prodavnice i druga „treća mesta“ od ključne važnosti za lokalnu demokratiju i vitalnost zajednice. Treća mesta moraju biti otvorena i lako dostupna onima koji ih zauzimaju. Oni takođe moraju biti susretljivi, što znači da zadovoljavaju potrebe svojih korisnika [1]

Sledeća teorijska osnova kojom se vodilo u ovom radu jeste „Okvir pozitivnog dizajna“, koji su razvili Pieter Desmet i Anna Pohlmeyer. Njihov istraživački rad ukazuje na vrednost primene perspektive usmerene na čoveka u procesu dizajniranja, tj. svrha je da pomognu onima koji žele izričito da dizajniraju za subjektivno blagostanje ili da istraže uticaj dizajna na sreću ljudi.

Okvir za pozitivan dizajn predstavlja pristup dizajnu za ljudski procvat. Sve tri opisane komponente za dizajn mogu pojedinačno da doprinesu subjektivnom blagostanju osobe, ali sva tri su potrebna da bi osoba procvetala. Pod procvatom se podrazumeva život u potpunosti, odnosno biti najbolja verzija sebe. Ljudi koji cvetaju imaju dublji osećaj svrhe i smisla života, ali takođe doživljavaju česte pozitivne emocije. Sve u svemu, pozitivan dizajn obuhvata čitav život ljudi i zajednica, uključujući sve aspekte subjektivnog blagostanja. Koncept rada je da ako proizvodi funkcionišu kao resursi koji se bave značajnim ciljevima, onda mogu doprineti sreći korisnika [2].

Nisu proizvodi niti njihova materijalna vrednost ono što nas može učiniti srećnim, već ono što radimo sa proizvodima [3].

\section{DIZAJN ENTERIJERA KAFETERIJE}

Pozicija sedenja u prostoru i samo cirkulisanje kroz isti jeste najbitniji funkcionalni aspekt. $U$ zadatom projektu sagledani su svi aspekti mogućeg ponašanja korisnika, prostor je organizovan smisleno i funkcionalno, i u skladu sa prethodnim istraživanjima. Ceo prostor podeljen je na tri etaže, odnosno 3 zone i formiran je tako da ima zone za sve tipove individue, što predstavlja i sam koncept projekta.

Prvu zonu čini prostor sa funkcijom kafea u prizemlju, tu se nalazi nisko sedenje, lounge deo, visoko sedenje uz same izloge lokala, koji daju mogućnost gostima da sede sami ili u paru. U sklopu šanka takođe postoji visoko sedenje, obezbeđen je dovoljan prostor za skladištenje svih potrebnih namirnica, kao i za obavljanje osnovnih funkcija unutar njega (prostor za pranje posuđa, pravljenje kafe, izdavanje porudžbina i kasa). U projektu su predviđeni i prostori magacina odmah do samog šanka na prizemlju i spratu, kao i u suterenu. 


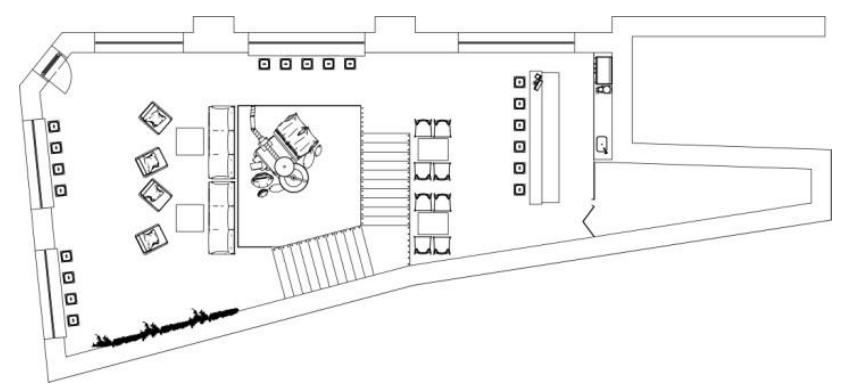

Slika 9. Osnova prizemlja kafeterije [9]

Druga zona je prostor namenjen jednim delom prodaji kafe, dok je u drugi deo smešten veći zajednički sto, namenjen organizovanju grupnih sastanaka. Deo sa prodavnicom kafe, pored polica sa proizvodima, sadrži pultove za naplatu i izdavanje, i za samouslužno degustiranje kafe sa dodacima kao što su mleko i šećer.

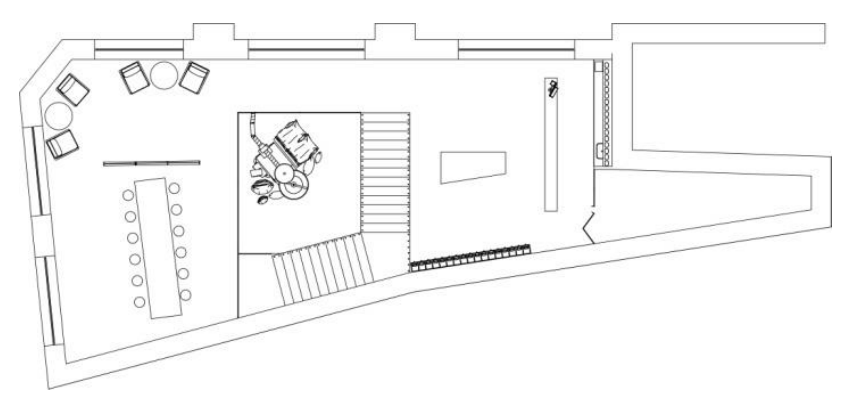

Slika 10. Osnova sprata kafeterije [10]

Treća zona smeštena je u suterenu, gde se nalazi glavni element - mašina za prženje kafe, koja je otvorena ka svim etažama, tako da korisnicima bude pružen maksimalni doživljaj, od vizuelnog prikaza procesa prerade kafe, do neodoljivog mirisa i ispijanja samog napitka. Atrijum je uokviren stepeništem, kojima se dolazi do toaleta za goste, svlačionice za zaposlene, magacina i kotlarnice u suterenu.

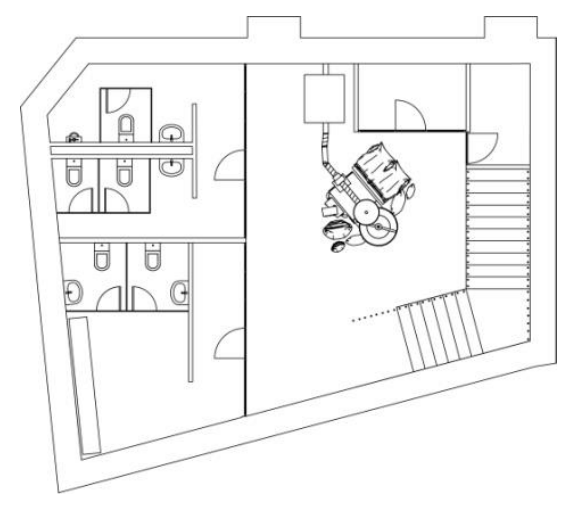

Slika 11. Osnova suterena kafeterije [11]

\section{ZAKLJUČAK}

Istražujući već postojeće prostore kafeterija tog tipa, bitne karakteristike dizajna tih prostora, kao i ponašanje i potrebe posetioca, pokazuje da su ta istraživanja od značaja i u velikoj meri doprinose adekvatnom projektovanju kafeterije prema afinitetima korisnika.

Uzimajući u obzir da se socijalne kulture ljudi razlikuju u zavisnosti od lokacije, ovakvo istraživanje bi bilo potrebno ponovo sprovesti ukoliko se radi o drugom lokalitetu.

Koja god da je namena prostora u pitanju, za adekvatno dizajniran prostor potrebno je poznavati socijalne karakteristike korisnika, takođe i kako dizajn prostora utiče na stvaranje ambijenta i na društvene interakcije u njemu.

Kada je reč o projektovanju enterijera određenog prostora, potrebno je naglasiti da je neophodno da dizajner posmatra druge prostore tog tipa na obližnjim lokacijama, i uočiti potrebe i ponašanja ljudi u tim prostorima. Posmatrati značaj osvetljenja, oblik nameštaja, rastojanja, raspored mobilijara, funkcionisanje u prostoru, itd.

Dobro osmišljen prostor, odnosno prema afinitetima korisnika, poboljšava njihova iskustva u njemu, pruža im energiju, inspiraciju $i$ podstiče na komunikaciju sa drugima. Biti na dobro osmišljenom mestu dovodi do željenog emocionalnog stanja.

\section{LITERATURA}

[1] Jeffres, Leo W.; Bracken, Cheryl C.; Jian, Guowei; Casey, Mary F.; The Impact of Third Places on Community Quality of Life, Applied Research in the Quality of Life, 2009.

[2] Pieter M. A. Desmet and Anna E. Pohlmeyer, Positive Design: An Introduction to Design for Subjective WellBeing, Faculty of Industrial Design Engineering, Delft University of Technology, Netherlands

[3] Ben-Shahar, T., Happier: Can you learn to be happy? , Berkshire, UK: McGraw-Hill, 2008.

\section{Kratka biografija:}

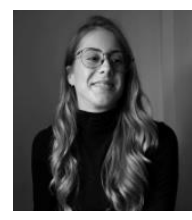

Dragana Milić rođena je u Novom Sadu 1993. god. Master rad na Fakultetu tehničkih nauka iz oblasti Arhitektura i urbanizam Projektovanje enterijera odbranila je 2021.god. kontakt: gaga_milic@hotmail.com 